\title{
Woven EndoBridge Intrasaccular Flow Disrupter for the Treatment of Ruptured and Unruptured Wide-Neck Cerebral Aneurysms: Report of 55 Cases
}

D. Behme, A. Berlis, and W. Weber

\begin{abstract}
BACKGROUND AND PURPOSE: The safety and efficacy of the Woven EndoBridge (WEB) device for the treatment of cerebral aneurysms have been investigated in several studies. Most of these studies focused on specific aneurysms or a certain WEB device. Our objective was to report the experience of 2 German centers with the WEB device, including technical feasibility, safety, and short-term angiographic outcome.
\end{abstract}

MATERIALS AND METHODS: We performed a retrospective study of all ruptured and unruptured aneurysms that were treated with a WEB device (WEB Double-Layer, Single-Layer, and Single-Layer Sphere) between April 2012 and August 2014. Primary outcome measures included the feasibility of the implantation and the angiographic outcome at 3-month follow-up. Secondary outcome measures included the clinical outcome at discharge and procedural complications.

RESULTS: Fifty-five aneurysms in 52 patients, including 14 ruptured aneurysms, underwent treatment with the WEB device. The median age of patients was 55 years (range, 30-75 years); 19/55 (37\%) were men. The device could be deployed in all patients and was implanted in 51/55 (93\%) cases. Procedural complications occurred in 6/51 (12\%), comprising 2 thromboembolic events, 2 thrombus formations, 1 high-grade posterior cerebral artery stenosis, and 1 aneurysm rupture. None of these had clinical sequelae. Angiographic follow-up at 3 months was available for 44/51 (86\%) aneurysms. A favorable angiographic result at 3 months was achieved in 29/44 (66\%) cases, whereas the percentage of good anatomic results increased from $40 \%$ in 2012 to $75 \%$ in 2014 .

CONCLUSIONS: The WEB device proved to be safe. Acceptable occlusion rates can be achieved but seem to require wide experience with the device.

ABBREVIATIONS: ASA = acetylsalicylic acid; $\mathrm{DL}$ = Double-Layer; $\mathrm{SL}=$ Single-Layer; SLS = Single-Layer Sphere; WEB = Woven EndoBridge

E ndovascular treatment has become a widely accepted thera- peutic option for ruptured and unruptured cerebral aneurysms. ${ }^{1-4}$ Wide-neck or large aneurysms are difficult to treat by coil embolization without the use of intraluminal support devices

Received October 25, 2014; accepted after revision February 6, 2015.

From the Department of Neuroradiology (D.B.), Georg-August-University Göttingen, University Medical Center, Göttingen, Germany; Department of Neuroradiology (A.B.), Klinikum Augsburg, Augsburg, Germany; Departments of Radiology and Neuroradiology (W.W.), Ruhr-University-Bochum, University Medical Center, Bochum Langendreer, Departments of Radiology and Neuroradiology, Bochum, Germany

D.B. and W.W. changed departments in July 2014. Treatment of the patients was performed at Recklinghausen and Augsburg.

Paper previously presented in part at: Annual Meeting of the Germany Society of Neurosurgeons, May 11-14, 2014; Dresden, Germany; and the Annual Meeting of the Workshop Interventional Neuroradiology (WIN), May 15-16, 2014; Hamburg, Germany.

Please address correspondence to Daniel Behme, MD, Georg-August-University Göttingen, University Medical Center, Department of Neuroradiology, 37099 Göttingen, Germany; e-mail: daniel.behme@med.uni-goettingen.de

http://dx.doi.org/10.3174/ajnr.A4323 such as balloons or stents. When these devices are used for the treatment of complex cerebral aneurysms, promising results have been reported. ${ }^{5,6}$ Nevertheless, there are several limitations in the use of intraluminal support devices, such as the risk of interventional complications or the need for dual anitplatelet therapy in the case of stent-assisted coil embolization. ${ }^{7,8}$ The Woven EndoBridge (WEB; Sequent Medical, Aliso Viejo, California) is an intrasaccular flow-disruption device that modifies blood flow at the aneurysm neck. ${ }^{9}$ Today the WEB is available in 3 different shapes: the WEB Double-Layer (DL), Single-Layer (SL) and Single-Layer Sphere (SLS). ${ }^{10}$ So far, initial clinical results have mostly been published for the WEB-DL, comprising the results of a prospective, multicenter study and several case series. Additionally, there are only very limited data about the feasibility of the WEB device for the treatment of ruptured aneurysms. ${ }^{10}$ Occlusion rates of $81 \%-92 \%$ have been reported when the WEB-DL was implanted. ${ }^{11-13}$ In ruptured aneurysms, occlusion rates of $67 \%$ have been reported. ${ }^{10}$ All studies reported high rates of neck remnants, 
which have been shown to represent an inflow into the recess of the WEB-DL in many cases. ${ }^{1-13}$ To our knowledge, none of these studies reflect experience with ruptured and unruptured aneurysms that have been treated with all 3 types of WEB devices.

\section{MATERIALS AND METHODS}

We conducted a retrospective study of all patients who underwent endovascular therapy for the treatment of ruptured or unruptured cerebral aneurysms using the WEB device between April 2012 and August 2014 at 2 German centers. The indication for treatment and the technique chosen were decided for all aneurysms by a multidisciplinary team, consisting of neurosurgeons and interventional neuroradiologists in each center. All 3 types of the WEB device (DL, SL, and SLS) were used for treatment of the aneurysms. Each of the devices received a European Confirmatory Mark for the treatment of unruptured and ruptured aneurysms. According to the guidelines of the local ethics committee, no approval was necessary. The WEB device is a self-expanding, braided nitinol mesh. The Dual-Layer device is constructed with 2 compartments formed by inner and outer braids held together by proximal, middle, and distal radiopaque markers. The WEB-DL is braided with 216 or 288 nitinol wires, depending on the device size. The WEB-SL and the WEB-SLS devices were launched in 2013; these devices are braided like the dual-layer, but they form only a single-layer device that is oblate and either of globular or spheric geometry, facilitating a lower profile of the device. The WEB is fully retrievable before implantation, and it can be delivered through a 0.027 -inch microcatheter. The device uses an electrothermal detachment system. Anitplatelet and anticoagulation regimens were the following: After the first patient had a thromboembolic complication at Center A, all patients with unruptured aneurysms received $100 \mathrm{mg}$ acetylsalicylic acid (ASA) and $75 \mathrm{mg}$ clopidogrel 5 days before treatment. ASA was continued for 6 weeks if no additional stent placement was performed. Clopidogrel was stopped after implantation of the WEB. If additional stent placement was performed, clopidogrel was continued for 6 weeks, and ASA, for 6 months. During the procedure, a bolus of 5000 IU heparin was administered, and systemic heparinization was continued for 48 hours. Heparin administration was then adjusted with activated clotting time, aiming for 2-3 times. At Center B, all patients with unruptured aneurysms received 100 mg ASA for 1 month of treatment; additionally, a bolus of $5000 \mathrm{IU}$ heparin was administered during the endovascular procedure in general, before the detachment of the device. In cases of ruptured aneurysms, patients received $100 \mathrm{mg}$ ASA for 6 weeks at Center A and no anitplatelet drugs at Center $B$ if not required for other medical conditions.

All clinical data were taken from the electronic patient records. Clinical assessment at admission and discharge was performed by a consultant neurosurgeon. The angiographic and all other imaging data were re-evaluated by 2 senior neuroradiologists (W.W. and A.B.). Occlusion results were categorized into the following: complete, neck remnants with real inflow into the neck, neck remnants with inflow into the marker recess of the device, and aneurysm remnants. A favorable result was defined as complete occlusion or a neck remnant. Only DSA images were used for the evaluation of the occlusion results. Primary outcome measures were the technical feasibility of the WEB implantation and angiographic outcome at 3 months or at first angiographic control if the control was before 90 days of treatment. Secondary outcome measures were clinical outcome at discharge and procedural complications of the WEB implantation. Subgroups of interest were identified a priori, and statistical comparisons among these cohorts were performed by using contingency tables and the Fisher exact test. Statistical analyses were performed with GraphPad Prism Software, Version 6.01 (GraphPad Software, San Diego, California). A $P$ value $\leq .05$ was considered statistically significant.

\section{RESULTS}

We identified 52 patients with 55 aneurysms who underwent an endovascular treatment using the WEB device between April 2012 and August 2014. Fourteen of 55 (25\%) aneurysms were ruptured. Four of $52(8 \%)$ patients in this series also participated in the Woven Endoluminal Bridge Clinical Assessment of intraSaccular aneurysmal Therapy study. ${ }^{14}$ The median age of patients was 50 years (range, 30-75 years); 19/55 (35\%) were men. The WEB could be implanted in 51 aneurysms. In an additional 4 cases, the WEB was deployed but not implanted. The aneurysm locations in these were the following: the MCA in 2 cases, anterior communicating artery in 1 case, and the carotid-T in 1 case. The device was not implanted because of inappropriate sizing in all 4 cases. In 2 cases, the deployment led to a stenosis of an adjacent vessel, which was completely reversed after the WEB was removed. Neither vessel stenosis led to persistent impairment. Aneurysm location was the middle cerebral artery in 19/51(37\%) (Fig 1); the anterior communicating in $9 / 51$ (18\%); the basilar artery in $10 / 51$ (20\%) (Fig 2); the posterior communicating artery in 4/51 (8\%); the carotid-T in 4/51 (8\%); and 4/51 (6\%) internal carotid artery, anterior cerebral artery, and superior cerebellar artery in $1 / 51$ each $(2 \%)$. Aneurysm size was the following (median, range): neck, $5 \mathrm{~mm}$ (2-8 $\mathrm{mm})$; dome, $7 \mathrm{~mm}(3.2-12 \mathrm{~mm})$; and aneurysm height, $7 \mathrm{~mm}(4-15 \mathrm{~mm})$. Forty-one of $51(80 \%)$ aneurysms had a neck of $\geq 4 \mathrm{~mm}$. In those patients with ruptured aneurysms, the location was the MCA in 6/14 (43\%); the anterior communicating artery in $3 / 14(21 \%)$; the posterior communicating artery in $2 / 14(14 \%)$; the superior cerebellar artery in $1 / 14$ (7\%); the anterior cerebral artery, carotid-T 1/14 (7\%) each, and posterior inferior cerebellar artery in $1 / 14$ each (7\%). The sizes of the ruptured aneurysms were the following: neck, $4.5 \mathrm{~mm}$ (range, 3.2-7.8 mm); dome, $6.7 \mathrm{~mm}$ (range, 3.4-9 $\mathrm{mm}$ ); and height, 6.6 $\mathrm{mm}$ (range, $4-14 \mathrm{~mm}$ ).

Clinical presentation of those patients with ruptured aneurysms was Hunt and Hess grades 1 and 2 in 4 cases each, Hunt and Hess 3 in 5 cases, and Hunt and Hess 4 in 1 case. Clinical outcome at discharge was favorable $(\mathrm{mRS} 0+1)$ in $11 / 14(79 \%)$ ruptured aneurysms. Three of $14(21 \%)$ patients died within the acute phase of the acute subarachnoid hemorrhage. In the cohort with unruptured aneurysms, 37/37 (100\%) had a favorable outcome $(\mathrm{mRS} 0+1)$ at discharge. Of those patients with mRS $1(5 / 37), 3$ had been mRS 1 before treatment, 1 had a stroke caused by a thromboembolic complication, and the other had acute SAH after an accidental aneurysm rupture (Table).

Short-term angiographic results were available for $44 / 51$ 


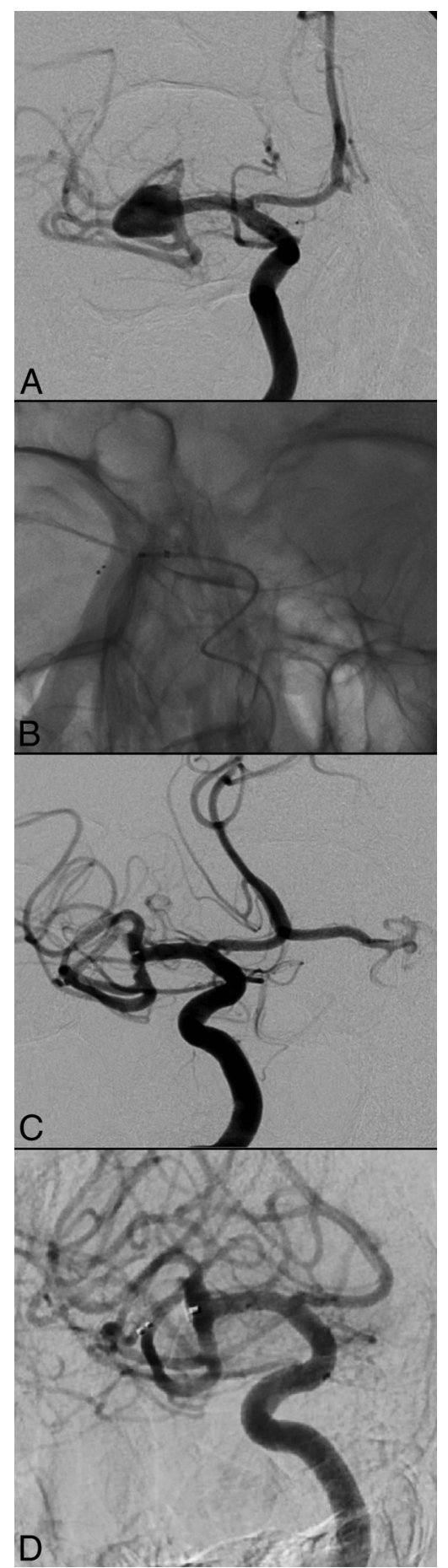

FIG 1. Unruptured MCA aneurysm of the right side, treated with a WEB-DL $9 \times 6 \mathrm{~mm}$. A, Initial angiogram of the aneurysm. $B$, Unsubtracted image after deployment of the WEB-DL $9 \times 6 \mathrm{~mm}$. C, Initial result after implantation of the WEB. $D$, Angiographic follow-up after 10 months, confirming stable occlusion of the aneurysm.

(86\%) at 99 days (range, $8-471$ days) after treatment. In 15/44 $(34 \%)$ cases, a total occlusion was observed. In another $14 / 44$ (32\%) cases, a neck remnant was present, where 11/14 (79\%) showed real inflow into the aneurysm neck and 3/14 (21\%) were classified as inflow into the marker recess.

In the remaining 15 cases, an aneurysm remnant was observed. All of these 15 patients underwent endovascular retreat- ment. Y-stent placement with additional coil embolization was performed in 8/15 (53\%) (Fig 2); additional stent placement without coil embolization, in 1 ; and coil embolization without the use of an intraluminal support device was used in the remaining 6 cases.

A favorable angiographic result (complete occlusion or neck remnant) was achieved in 23/35 (66\%) unruptured aneurysms and in $6 / 9(67 \%)$ ruptured aneurysms $(P=1.0)$. When the WEB-SL or -SLS was used, favorable results were achieved in $65 \%$ $(15 / 23)$ compared with $14 / 21$ (67\%) when the WEB-DL was deployed $(P=1.0)$. Most interesting, we found a rate of $83 \%(5 / 6)$ favorable angiographic results when the WEB-SL was used in ruptured aneurysms. When analyzing the occlusion results according to the site of the aneurysms, we found favorable results to be the lowest in anterior communicating artery aneurysms, with 38\% compared with $71 \%$ in the MCA and $71 \%$ in basilar artery aneurysms. Comparing the anatomic results at 3 months according to the year of treatment, we found that the percentage of favorable angiographic results increased from only $40 \%$ in 2012 to $68 \%$ in 2013 and reached $75 \%$ in 2014 (Fig 3). The number of treatments with follow-up available was 5 in 2012, 31 in 2013, and 8 in 2014.

For all patients (15/29) who had a second follow-up and who did not undergo retreatment after the initial implantation of the WEB, we could prove stable results compared with the first angiographic control at 360 days (range, 84-470 days) after treatment. Notably, all neck remnants (real and inflow into the marker recess) were stable at the time of the second control.

For those who received retreatment of an aneurysm remnant, we found aneurysms to be totally occluded or showing a neck remnant in only 5/10 (50\%) cases.

In general, complications occurred in 6/51 (12\%) cases (Table). In 4 cases, thrombus formation occurred in distal vessel branches; 2 resolved completely after therapy with abciximab (ReoPro); another resolved incompletely after administration of intra-arterial tissue plasminogen activator, leading to an incomplete infarction of the left posterior cerebral artery territory; and the remaining case resolved incompletely after treatment with tirofiban (Aggrastat), leading to a partial infarction of the right MCA territory. One of the patients who had a thromboembolic infarction did not develop any symptoms after the intervention. The other developed a weakness of the left arm after treatment that was completely resolved at discharge. In 1 case, the implantation of the WEB device into a basilar artery tip aneurysm led to a stenosis of the right posterior cerebral artery $\mathrm{P} 1$ segment, which had to be stented (Fig 2). In this case, eptifibatide (Integrilin) was administered for 24 hours and the patient was subsequently treated with ASA and clopidogrel. The patient did not develop any clinical symptoms. Additionally, 1 aneurysm rupture caused by the microcatheter occurred; the patient received additional treatment with a stent and coils. This patient developed a paresis of his left leg (mRS 1 at discharge).

The retreatment procedures were performed without complications. One patient had an in-stent thrombosis after Y-stent placement 10 days after the retreatment procedure because he had stopped the dual antiplatelet medication on his own. 


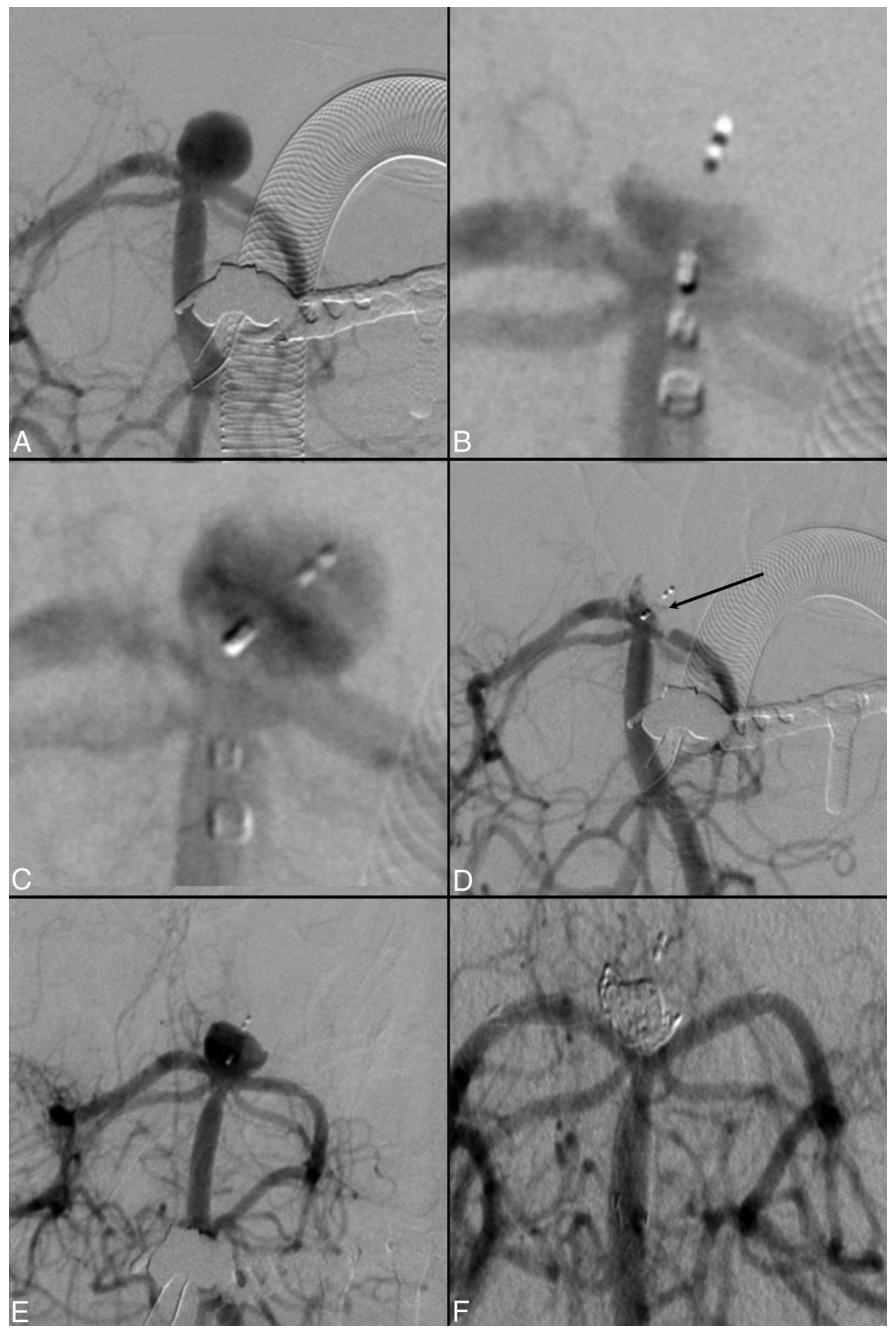

FIG 2. Unruptured basilar artery tip aneurysm and posterior cerebral artery stenosis after migration of the WEB and retreatment with stent and coils. A, Initial angiogram of the aneurysm. B, Deployment of the WEB-DL $7 \times 4 \mathrm{~mm}$. C, Migration of the device toward the left side of the aneurysm. D, High-grade stenosis of the left posterior cerebral artery P1 segment (arrow), which was stented subsequently with a Neuroform stent (Stryker Neurovascular, Fremont, California). E, Control angiogram at 3 months shows an aneurysm remnant. F, Aneurysm occlusion after Y-stent placement (Low-Profile Visualized Intraluminal Support Device; MicroVention, Tustin, California) and additional coil embolization.

\section{DISCUSSION}

Our findings confirm the results of the previously published case series and the preliminary results of the Woven Endoluminal Bridge Clinical Assessment of intraSaccular aneurysmal Therapy study regarding safety, technical feasibility, and high rates of favorable outcome of the device. The results do not confirm the very high rates of favorable occlusion results that have been reported previously. ${ }^{11-15}$

The deployment of the WEB device was feasible in all 55 aneurysms, and it was finally implanted in 51/55 (93\%) cases, which is a rate of technical success comparable with that reported in the literature. ${ }^{1,13}$ Complications occurred in 6/51 (12\%) cases in our 


\begin{tabular}{|c|c|c|c|c|c|c|}
\hline No. & $\begin{array}{l}\text { Aneurysm } \\
\text { Location }\end{array}$ & $\begin{array}{c}\text { Neck } \\
\text { Size }(\mathrm{mm})\end{array}$ & $\begin{array}{l}\text { Device, } \\
\text { Size }\end{array}$ & $\begin{array}{c}\text { Status } \\
\text { (Ruptured/Unruptured) }\end{array}$ & Complication & $\begin{array}{c}\text { Outcome at } \\
\text { Discharge (mRS) }\end{array}$ \\
\hline 1 & BA tip & 5.5 & $\mathrm{DL}, 7 \times 4$ & Unruptured & Pl stenosis & 0 \\
\hline 2 & BA tip & 8.0 & $\mathrm{DL}, 10 \times 7$ & Unruptured & $\begin{array}{l}\text { Thromboembolic infarction } \\
\text { left PCA territory }\end{array}$ & 0 \\
\hline 3 & BA tip & 4.5 & $\mathrm{DL}, 5 \times 3$ & Unruptured & $\begin{array}{l}\text { Thrombus formation, } \\
\text { no infarction }\end{array}$ & 0 \\
\hline 4 & MCA & 5.0 & $\mathrm{DL}, 6 \times 3$ & Unruptured & $\begin{array}{l}\text { Thromboembolic with } \\
\text { MCA infarction }\end{array}$ & 0 \\
\hline 5 & MCA & 5.5 & $\mathrm{DL}, 7 \times 6$ & Unruptured & $\begin{array}{l}\text { Thromboembolic with } \\
\text { MCA infarction }\end{array}$ & 1 \\
\hline 6 & AcomA & 4.1 & $\mathrm{SL}, 6 \times 4$ & Unruptured & Aneurysm rupture & 1 \\
\hline
\end{tabular}

Note:-BA indicates basilar artery; AcomA, anterior communicating artery; PCA, posterior cerebral artery.

Percentage of favorable angiographic results (RR I+II) after treatment according to the year of treatment

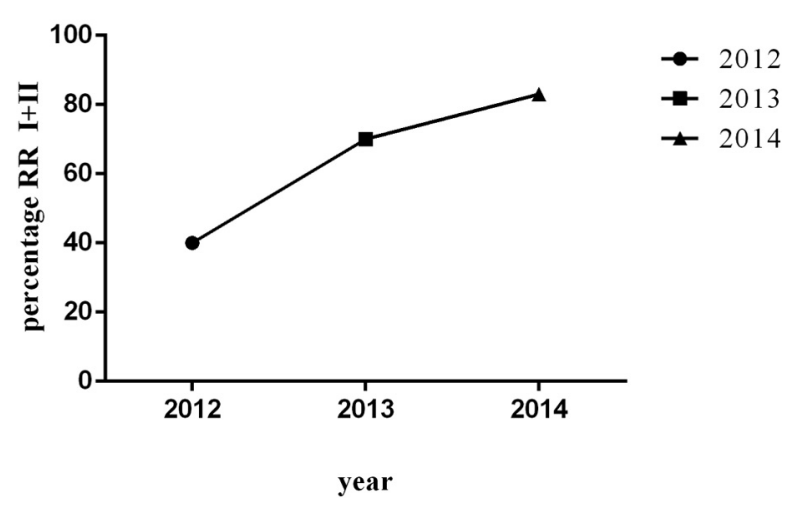

FIG 3. "Learning curve" showing the percentage of successful treatments from 2012 to 2014.

series, which is similar to those found by Papagiannaki et $\mathrm{al}^{13}$ and Pierot et al ${ }^{12}$ when the WEB was used for aneurysm embolization. In this study, thrombus formation occurred in 2 cases and was resolved completely after medical treatment; in 2 other cases, thromboembolic complications occurred that caused cerebral infarction. A rate of 2/51 (4\%) thromboembolic complications, therefore, is very low compared with that published so far when the WEB was used. ${ }^{11,13}$ When competing techniques such as stents or balloons have been deployed for the treatment of wideneck cerebral aneurysms, much higher rates of thromboembolic complications were found. ${ }^{16}$ A special concern of the treatment is the comparatively large microcatheter necessary for the delivery of the device, which might lead to higher rates of aneurysm rupture because of its rigidity. Nevertheless, this study found aneurysm rupture to be a rare event $(2 \%)$, which was not more frequent than that reported in the Clinical and Anatomical Results in the Treatment of Ruptured Intracranial Aneurysms series or the Analysis of Treatment by Endovascular Approach of Nonruptured Aneurysms trial. ${ }^{17,18}$ The overall complication rate in our series remains comparatively low when adding the complications of the 15 retreatment procedures, with only 1 thrombotic occlusion of a stent, which happened after the patient stopped his medication with ASA and clopidogrel autonomously.

Taking into account that one-third of the aneurysms in our series are MCA aneurysms that also could have been treated surgically, we compared the complication rates with those in large trials that investigated complications in the clipping of unrup- tured aneurysms. Barker et $\mathrm{al}^{19}$ in 2004 reported about 7.8\% neurologic complications and $6.4 \%$ occluded arteries after surgical clipping, whereas only $2 / 51$ (4\%) of the patients in our series had a neurologic complication or a thrombotic event that led to an infarction. Others found the rate of neurologic complications to be $7.4 \%$ and the occlusion of cerebral arteries to be $4.2 \%$, also slightly higher rates compared with those in our series. ${ }^{20}$

The treatment with the WEB led to high rates of favorable clinical outcome at discharge in unruptured $(100 \%$, mRS $0+1)$ and ruptured $(79 \%$, mRS $0+1)$ aneurysms. Compared with what is known from the Analysis of Treatment by Endovascular Approach of Nonruptured Aneurysms trial (transient and permanent neurologic deficits in 5.4\%) and the International Subarachnoid Aneurysm Trial (23.7\% mortality and morbidity), these results are very promising and confirm what has been known about clinical outcome after treatment with the WEB. ${ }^{1,18}$

The rate of favorable angiographic results at 3 months was comparatively low, with $66 \%$ in this series. Others reported favorable occlusion results of $81 \%-92 \%$ when the WEB was used for aneurysm occlusion. ${ }^{11-13}$ Caroff et $\mathrm{al}^{10}$ found occlusion rates as low as $67 \%$ in ruptured wide-neck aneurysms when treated with the WEB device, which is comparable our findings.

In this series, the occlusion rate did not depend on the aneurysm location or the device used (SL versus DL) or on the aneurysm status (ruptured versus unruptured). Most interesting, we found that the rate of favorable angiographic results at 3 months was the highest in 2014 compared with 2012 and 2013, with 75\% in 2014 versus only $40 \%$ in 2012, strongly indicating that experience is a prerequisite for successful use of the device, especially in terms of sizing, because feasibility was high and complication rates were low in all years. Furthermore, there was no rerupture when the WEB was used to treat patients with acute SAH. In addition, occlusion results were stable in those patients who underwent a midterm follow-up after treatment with a WEB alone but not in those with additional endovascular treatment, indicating that the WEB might lead to more stable anatomic results in wide-neck aneurysms compared with stent placement or balloon remodeling if the device was initially occluding the aneurysm.

Why occlusion rates are lower in this series remains uncertain; most likely the results are biased by the high rate of unfavorable occlusions in 2012 and the beginning of 2013, which were basically caused by undersizing the device.

The basic limitations of this study are the retrospective design and the low number of cases. Additionally, the adjudication of the 
end points (eg, angiographic results, complications, and clinical outcome) was performed at the reporting site, without a core laboratory or requirement of an independent adjudicator. All statistical analyses might be underpowered due to the limited number of cases, and long-term controls are necessary to prove the efficacy of the device.

\section{CONCLUSIONS}

The deployment and implantation of the WEB device proved feasible and safe. Nevertheless, wide experience seems to be a prerequisite to achieve acceptable occlusion rates with the device. Larger studies are necessary to investigate the feasibility and results, especially with the recently introduced WEB-SL and WEB-SLS.

Disclosures: Daniel Behme-UNRELATED: Support for Travel to Meetings for the Study or Other Purposes: Sequent Medical (travel to German Society of Neurosurgery Meeting, Dresden, Germany); Other: minor speaking honoraria from Sequent Medical. Ansgar Berlis—RELATED: Consulting Fee or Honorarium: Sequent Medical (proctoring), MicroVention (proctoring), Covidien (proctoring); Support for Travel to Meetings for the Study or Other Purposes: Sequent Medical, MicroVention, Covidien, Stryker, Penumbra; UNRELATED: Consultancy: proctoring and consultancy agreements with Sequent Medical, Covidien, and Stryker; Payment for Lectures (including service on Speakers Bureaus): Sequent Medical, Covidien, MicroVention, Stryker, Penumbra. Werner Weber-RELATED: Consulting Fee or Honorarium: proctor for the WEB device; UNRELATED: Consultancy: proctor for the WEB device in Europe; Other: participation in the Woven Endoluminal Bridge Clinical Assessment of Intrasaccular Aneurysmal Therapy I.

\section{REFERENCES}

1. Molyneux A, Kerr R, Stratton I, et al. International Subarachnoid Aneurysm Trial (ISAT) of neurosurgical clipping versus endovascular coiling in 2143 patients with ruptured intracranial aneurysms: a randomised trial. Lancet 2002;360:1267-74

2. Henkes H, Fischer S, Weber W, et al. Endovascular coil occlusion of 1811 intracranial aneurysms: early angiographic and clinical results. Neurosurgery 2004;54:268-80; discussion 280-85

3. Pierot L, Spelle L, Vitry F. Immediate anatomic results after the endovascular treatment of unruptured intracranial aneurysms: analysis of the ATENA series. AJNR Am J Neuroradiol 2010; 31:140-44

4. Pierot L, Cognard C, Ricolfi F, et al. Immediate anatomic results after the endovascular treatment of ruptured intracranial aneurysms: analysis in the CLARITY series. AJNR Am J Neuroradiol 2010;31:907-11

5. Biondi A, Janardhan V, Katz JM, et al. Neuroform stent-assisted coil embolization of wide-neck intracranial aneurysms: strategies in stent deployment and midterm follow-up. Neurosurgery 2007;61: 460-68; discussion 468-69

6. Behme D, Weber A, Kowoll A, et al. Low-Profile Visualized Intralu- minal Support Device (LVIS Jr) as a novel tool in the treatment of wide-necked intracranial aneurysms: initial experience in 32 cases. J Neurointerv Surg 2015;7:281-85

7. Pierot L, Cognard C, Spelle L, et al. Safety and efficacy of balloon remodeling technique during endovascular treatment of intracranial aneurysms: critical review of the literature. AJNR Am J Neuroradiol 2012;33:12-15

8. Nishido H, Piotin M, Bartolini B, et al. Analysis of complications and recurrences of aneurysm coiling with special emphasis on the stentassisted technique. AJNR Am J Neuroradiol 2014;35:339-44

9. Ding YH, Lewis DA, Kadirvel R, et al. The Woven EndoBridge: a new aneurysm occlusion device. AJNR Am J Neuroradiol 2011;32:607-11

10. Caroff J, Mihalea C, Dargento F, et al. Woven EndoBridge (WEB) device for endovascular treatment of ruptured intracranial wideneck aneurysms: a single-center experience. Neuroradiology 2014; 56:755-61

11. Lubicz B, Klisch J, Gauvrit JY, et al. WEB-DL endovascular treatment of wide-neck bifurcation aneurysms: short- and midterm results in a European study. AJNR Am J Neuroradiol 2014;35:432-38

12. Pierot L, Klisch J, Cognard C, et al. Endovascular WEB flow disruption in middle cerebral artery aneurysms: preliminary feasibility, clinical, and anatomical results in a multicenter study. Neurosurgery 2013;73:27-34; discussion 34-35

13. Papagiannaki C, Spelle L, Januel AC, et al. WEB intrasaccular flow disruptor-prospective, multicenter experience in 83 patients with 85 aneurysms. AJNR Am J Neuroradiol 2014;35:2106-11

14. Pierot L, Spelle L, Costalat V, et al. E-029 WEB Flow Disruption: Preliminary Results from WEBCAST trial. J Neurointerv Surgery 2014;6(Suppl 1):A51

15. Pierot L, Liebig T, Sychra V, et al. Intrasaccular flow-disruption treatment of intracranial aneurysms: preliminary results of a multicenter clinical study. AJNR Am J Neuroradiol 2012;33:1232-38

16. Fargen KM, Mocco J, Neal D, et al. A multicenter study of stentassisted coiling of cerebral aneurysms with a Y-configuration. $\mathrm{Neu}$ rosurgery 2013;73:466-72

17. Cognard C, Pierot L, Anxionnat R, et al. Results of embolization used as the first treatment choice in a consecutive nonselected population of ruptured aneurysms: clinical results of the CLARITY GDC study. Neurosurgery 2011;69:837-41; discussion 842

18. Pierot L, Spelle L, Vitry F. Immediate clinical outcome of patients harboring unruptured intracranial aneurysms treated by endovascular approach: results of the ATENA study. Stroke 2008;39: 2497-504

19. Barker FG 2nd, Amin-Hanjani S, Butler WE, et al. Age-dependent differences in short-term outcome after surgical or endovascular treatment of unruptured intracranial aneurysms in the United States, 1996-2000. Neurosurgery 2004;54:18-28; discussion 28-30

20. Higashida RT, Lahue BJ, Torbey MT, et al. Treatment of unruptured intracranial aneurysms: a nationwide assessment of effectiveness. AJNR Am J Neuroradiol 2007;28:146-51 